\title{
A Pilot Usability Study of MINWii, a Music Therapy Game for Demented Patients
}

Mélodie Boulay ${ }^{\mathrm{ab}}$, Samuel Benveniste ${ }^{\mathrm{c} 1}$, Sandra Boespflug ${ }^{\mathrm{ab}}$, Pierre Jouvelot ${ }^{\mathrm{c}}$ and AnneSophie Rigaud ${ }^{\mathrm{ab}}$

${ }^{a}$ Assistance Publique-Hôpitaux de Paris Hôpital Broca 54 rue Pascal, 75013 Paris, France, ${ }^{\mathrm{b}}$ Université Paris Descartes, Faculté de Médecine, 15 rue de l'école de médecine, Paris, France,

${ }^{\mathrm{c}}$ MINES ParisTech, CRI, 35 rue Saint-Honoré, 77305 Fontainebleau, France

\begin{abstract}
MINWii is a music therapy game for the renarcissization of demented patients. It lets players improvise or play songs of their choice by pointing at a virtual keyboard with a Wiimote Pistol. We present the results of a three-month usability study we conducted with 7 institutionalized patients suffering from mild to moderately severe Alzheimer's disease at the LUSAGE Living Lab in Paris. We demonstrate that MINWii is indeed usable by AD patients despite their motor and cognitive impairments: our results, which were largely computed automatically thanks to MINWii's extensive logging capabilities, show either an instant mastery or a clear learning effect depending on patients' cognitive abilities. Moreover, patients were overall very satisfied with the game and expressed a desire to repeat the experience: MINWii fosters positive interaction with the caregivers and elicits powerful reminiscence with even the most severely impaired patients. This study justifies future research to assess the lasting effects of playing MINWii on both quality of life and cognitive impairment in demented patients.
\end{abstract}

\footnotetext{
${ }^{1}$ Corresponding author. Tel : +33164694844 or +336213978 88. Fax: + 33164694708 . Email: samuel.benveniste@mines-paristech.fr
} 
Keywords: Usability, Music Therapy, Dementia, Wiimote, Video Game.

\section{Introduction}

Alzheimer's Disease (AD) is a neurodegenerative disease and the most common cause of dementia among elderly people; it may impair several cognitive domains: memory, language, perceptual skills, attention, constructive abilities, orientation, problem solving and functional abilities [1]. This deterioration can be associated with behavioural and neuropsychiatric disorders such as wandering, irritability or delusional symptoms [2]. These disorders usually induce a loss of autonomy that leads to institutionalization in long-term care facilities.

Indeed, despite great research efforts, a drug capable of reversing or even stopping the cognitive decline of a significant number of demented patients has yet to be found. Therefore a majority of healthcare organizations (NHS, HAS, etc.) recommend using nonpharmacological means of intervention to help demented patients or ease the burden on their caregivers.

Taking into account these recommendations, occupational activities are increasingly implemented in nursing homes to help maintain patients' communication abilities and stimulate cognitive and physical capacities. These activities are led by a professional and can be performed either in a group or individually. Some studies highlight the effectiveness of occupational activities in demented patients. Graff et al. [3] have shown an improvement of patients' daily functioning after 10 sessions of occupational activities including cognitive and behavioural interventions. Similar results were found by Voigt-Radloff et al. [4] in another study.

Recently, Aimonetti [5] described a preliminary experiment of using the Wii as an occupational activity with old residents in a nursing home. The author empirically listed some 
possible benefits of playing Wii games: it allows doing physical and coordination exercises, even for people who are on a wheelchair; for those who can walk, the WiiFit game can help maintain balance; some programs such as "Cerebral Academy" can help stimulate memory and concentration; multiplayer games such as Wii Bowling also encourage communication and interaction with other residents and visitors, especially children. All of this in turn has psychological benefits such as increased self-esteem.

\subsection{Video Games and the Elderly}

Video games have been a significant form of entertainment since the 1970s, and the first studies regarding their use by the elderly were carried out in the early 1980 s. Some of these studies focused on the impact of playing video games on perceptual motor skills and response selection processing [6], [7], [8]. They showed positive effects on reaction times and coordination.

Other initiatives have shown beneficial effects of video games on some psychological parameters. In their study, Goldstein et al. [8] observed an increase of self-reported well-being in the experimental group after a Tetris training program (5 hours a week during 5 weeks). Similarly, McGuire [9] showed that elderly long-term care residents who played video games for eight weeks improved their self-esteem, whereas a control group did not. The same kind of observations were made when computers were introduced to people aged from 60 to 85 in nursing homes and senior citizen programs [10]. Observation of participants' reactions indicated increased feelings of self-esteem and mastery.

Various studies also have tried to demonstrate the effects of video gaming on seniors' cognitive functioning. Goldstein et al. [8] used the Stroop Color Word Test to assess the effects of playing Tetris on cognitive/perceptual adaptability, but no significant results were found. Results from a trial with 95 healthy older adults [11] showed an improvement of scores on tests of memory and attention in the experimental group who played $\mathrm{HiFi}$, a game 
designed to stimulate the ageing brain. A recent experiment [12], with the aim to see if training in a real-time strategy video game could attenuate cognitive decline in older adults, showed promising results. Participants were trained in the video game for 23.5 hours in order to improve their executive functions. The authors noticed an improvement in game performance, but also in some executive tasks such as switching, working memory, visual short-term memory and reasoning.

Neufeldt [13] has carried out a qualitative study with elderly people in a residential home. A group of six participants interacted with Wii Sports Bowling for six sessions. He observed an improvement of patients' coordination and movement capabilities, but also noticed that playing this video game was not as easy as often asserted for the elderly. Participants experienced difficulties with the use of the controller, by accidentally pressing inappropriate buttons. The author also observed that the time when actions had to be performed (press or release the button) was not as intuitive as expected.

Taking into account these data, video games can be seen as a means to slow down physical and cognitive deterioration due to age and to reinforce self-esteem. Thus, they are beginning to be used with the elderly in institutions. But this raises a problematic issue: older people are rarely familiar with new technologies and they can suffer from cognitive impairments. These two factors seem likely to make the use of traditional game interfaces too complex for old people, especially when they suffer from cognitive disorders such as AD.

The study carried out by Neufeldt [13] allowed him to gather information about usability problems experienced by elderly persons when playing Wii Sports Bowling. However, a lack of experimental data regarding usability testing of new interfaces such as the Wiimote with older patients remains, even though one of the main parameters that could predict the effectiveness of a technological intervention with patients is the customization of the application to meet their needs and the adaptation of the product use to their abilities. 


\subsection{Usability and Accessibility}

\subsubsection{Usability}

Usability has been widely described in the literature: it can be defined as "the extent to which a product can be used by specified users to achieve specified goals with effectiveness, efficiency and satisfaction in a specified context of use." [14]. Usability testing is a way of ensuring that systems are well adapted to the end-users and of guaranteeing that there are no potential negative outcomes that could result from their use. This procedure usually involves observing how users interact with prototypes or final technological products under controlled conditions. It seems necessary to assess which technological devices are adapted to AD patients and to empirically validate the features that would ease their use [15]. User-centric design is a notion that is in close relation with usability testing in the sense that, by involving the end-users throughout the design process, this approach allows them to influence the design of technological devices, which leads to better usability [16], [17]. With this method, we ensure that we meet the users' needs, and make technologies more accessible to elderly or disabled people.

\subsubsection{Accessibility}

Accessibility has been a concern for Human Computer Interface (HCI) designers for a long time; for example, screen readers for the blind were already under development in the early 1980s. However, physical disabilities like visual or hearing impairment and motor disabilities have remained the principal focus for a long time, while it took HCI researchers about 10 more years and a much more widespread use of computers to truly become interested in HCI design for cognitively impaired persons. Indeed, while enabling the first disability category mainly requires alternative means of conveying information such as screen readers, eye- 
tracking mice or head-operated joysticks, accessibility for the latter category often calls for modifications of the information itself in terms of structure, content and presentation, which has proven much more difficult to do.

However, an extensive literature now exists on this topic. Many authors [18], [19] divide cognitive disability issues in four main categories: perception and processing, memory, problem-solving and attention. Rowland proposes a list of modifications that can benefit users depending on which categories of issues they suffer from. These fixes can affect structure (chunking information with bullets and lists), content (pairing text with images) or presentation (adding white space to improve readability).

It is worth noting that this is not an exact science since those changes often induce a variety of trade-offs. For example, while Rowland [18] recommends avoiding animations to prevent distractions in attention-challenged individuals, other guidelines suggest using collapsible lists to only present users with a minimal amount of information at a time [19].

In any case, commercially available games usually do not respect basic game accessibility guidelines, and thus are not easily accessible for seniors [20].

\subsection{Justification for the Study}

Taking into account (1) the possible benefits of video games on physical, cognitive, and psychological functioning in elderly patients, (2) the recent attempts to use the Nintendo Wii with old and possibly cognitively impaired institutionalized people and (3) the lack of data regarding the usability of these applications, we decided to evaluate a simple game interface, MINWii.

MINWii [21] is a tool intended for the geriatric population, mixing music therapy (MT) and cognitive stimulation via video game technologies, specifically the Nintendo Wiimote. It seems relevant to offer cognitively impaired elderly people the possibility to take part in such 
an activity, since MT has been shown to lastingly reduce AD patients' anxiety levels, for example through a technique called U-Cycle Receptive MT [22]. Nevertheless, even though MT in its various forms has already been used extensively in institutions since WW2 [23], it has yet to be widely accepted as a worthy treatment method by physicians and the public at large. In this paper, we present a pilot usability study of MINWii [21] to enable AD patients to play their favourite melodies on a virtual keyboard.

\section{Materials and Methods}

\subsection{Population}

Seven patients hospitalized in a long term care unit at La Collégiale hospital (Paris, France) were recruited for this study (see Table 1). They all suffered from Alzheimer's disease according to NINCDS-ADRDA diagnosis criteria [1]. MMS score ranged from 12/30 to 22/30. The mean score was 16.71. The sample was composed of 4 women and 3 men, and the mean age of the group was 88.5 years (range: 77 -94). Written informed consent was obtained from all the participants or their family before the tests.

\subsection{System Description}

To design MINWii, researchers from MINES ParisTech collaborated with a team from the geriatric unit of another hospital (Saint-Maurice, near Paris), where the typical stay averages two months. There, voluntary patients suffering from mild to moderate cognitive impairment tested the system during weekly group sessions involving two to four participants.

The researchers used an iterative method, akin to Action Research [24], to repeatedly test and improve the system from session to session. This process, which had already proved its worth in a previous project with impulsive children [25], was very successful, as patients generally 
reported taking a lot of pleasure in the proposed activity and surprised their caregivers several times by showing unexpected skills, especially in terms of memory, when it came to music.

We decided to carry out the pilot study at La Collégiale hospital with patients hospitalized in long-term ward and able to participate in enough sessions to see trends emerge according to a research protocol. A reliable collection and interpretation of data had not been possible in the study carried out in Saint-Maurice hospital since the incremental design protocol implied making significant changes to the system from session to session.

A comprehensive description of MINWii and its three game modes is presented in another paper [21], which also covers the actual design process in detail. Here, we will only describe the specific features of the system that were used in our investigation. We only used one song and one of the three game modes available over a fixed number of sessions in order to make comparisons.

In this study, patients were seated in front of a large TV connected to a computer and given a Wiimote encased in a Wii Pistol (see Figure 1). A virtual keyboard, composed of coloured vertical strips, was displayed on the TV, with one of the strips made bigger and brighter than the others and displayed the corresponding lyrics (see Figure 2). Patients were then invited to play through Au clair de la Lune by pointing and clicking on the successively highlighted strips with a cursor displayed on screen as a large white dot. It is worth noting that the movements of the cursor were filtered and adjusted to make playing easier, although this had to be done at the expense of true pistol-like aiming, since the filtering would sometimes cause the cursor to appear noticeably off the actual place where the pistol was pointing, which slightly confused some of the patients (see below).

\subsection{Procedure}


Testing sessions took place once a week for approximately 10 to 20 minutes per patient, in the living room of the LUSAGE User Lab at La Collégiale/Broca hospital [26], [27]. Participants were accompanied by two psychologists during these sessions: one gave instructions and helped the patient if necessary, the other one carried out observations. An engineer was also present to launch the program. The procedure was as follows:

- $\quad$ First, one training session to allow patients to become familiar with the interface. That session started with three tasks designed to cover from the simplest action to the most complex one: 1) a single coloured strip was displayed on the screen; we asked the patient to aim at the strip and to press the trigger to produce a sound; 2) two coloured strips were present on the screen; the patient had to alternatively aim at each strip and to press the button to produce two different sounds; 3 ) a single coloured strip appeared at a random spot on the screen; each time the patient activated the note by aiming at it and pressing the trigger, the strip disappeared and reappeared elsewhere. We asked the patients to perform each step four times.

To finish the familiarization session, the "test song" (Au clair de la Lune) was played once.

- $\quad$ Second, three testing sessions with the test song played twice by the patients.

- Finally, a fourth testing session with the patient left alone in the room to see if an autonomous use of the interface was possible. The room configuration still allowed an exterior observation and interventions of the psychologist if necessary.

All sessions were video-recorded in order to carry out a precise analysis of the interface use by the patients.

\subsection{Measurements}

The following parameters have been assessed: 
1. Efficacy indicators: number of errors (click out of the right note) during each task;

2. Efficiency indicators: time to complete each task, number of verbal interventions provided by the moderator;

3. Satisfaction indicators: Satisfaction questionnaire with a five-point Likert scale, analysis of verbalizations and behaviour of the patient during the sessions.

Part of the data, including the number of errors and the time to complete tasks, was automatically recorded by the software. The analysis of behaviour, verbalizations, manipulation of the Wiimote and number of interventions was conducted a posteriori with the videos.

The satisfaction scale includes seven questions with responses going from «not satisfied» (=0 points) to «very satisfied » $(=4$ points $)$. The maximum score is 28 . The satisfaction questionnaire was administered twice, once after the training (familiarization) session and the second time after the third testing session.

\section{Results}

Among the 7 subjects of this experimentation, 2 patients did not complete the entire test. Subject A stopped after the $3^{\text {rd }}$ testing session because of medical problems and subject B refused to continue after the $2^{\text {nd }}$ testing session. However, we still decided to include their results in the analysis.

First, all of the patients succeeded in holding the Wiimote pistol properly from the first training session on. This observation is supported by the data we collected through the Wiimotes, which show that all of the patients except subject B completed this task relatively fast. However, performance analysis during this brief training phase will not be detailed here 
because the proposed tasks were too different from the rest. We thus decided to start our result description from the first actual testing session.

The time needed to complete the task significantly decreased from the first to the second session for 6 participants (see Figure 3). Only subject B took longer to complete the $2^{\text {nd }}$ session than the first one. Broadly, the patients kept going faster to complete the task from one session to another. However, we observed an increase of the time taken to complete the individual (i.e. unassisted) session for 2 patients (C, D). Patient F's speed performance was very good from the beginning and remained relatively stable during all the sessions.

We observed a decreasing trend for the number of errors made while playing the game (click outside of the right note) from one session to another for 4 participants (see Figure 4). Patient $\mathrm{B}$ made more mistakes in the $2^{\text {nd }}$ session than during the first one, and patient $\mathrm{F}$ made more mistakes in the $3^{\text {rd }}$ and in the last session than in the two first ones. Number of errors made by subject $\mathrm{D}$ remained stable from the $1^{\text {st }}$ session on.

The number of verbal interventions by the moderator substantially decreased throughout the sessions for subject $A$ and $G$ (see Figure 5). Three patients required only very few verbal instructions from the beginning $(\mathrm{C}, \mathrm{E}, \mathrm{F})$. The number of verbal interventions was more important for subject B from session 1 to session 2, and tended to remain the same for subject $\mathrm{D}$ in each session.

There were only a very small number of physical interventions by the moderator during the testing sessions (see Table 2). Among the 7 participants, 3 did not need any physical help at all during the game, and 3 only needed one or two interventions during one session. Subject B was given physical help many more times than the other participants in the two sessions she completed. 
According to the satisfaction scale, participants were quite pleased with the activity (see Table 3). The total mean score for the two questionnaires was 17.7/28. Mean scores for questionnaire 1 (after the training session) and questionnaire 2 (after the third testing session) were similar (17.57 vs. 17.85). Five participants (A, C, D, F, G) expressed the same satisfaction degree after the training session and after the third testing session. Patient B was less satisfied at the time of the second satisfaction evaluation, than in the beginning of the test phase. Patient E was more and more satisfied throughout the sessions.

\section{Discussion}

\subsection{Motor Aspects}

\subsubsection{Age-related Motor Impairment}

We observed that physical disabilities due to age (i.e. degenerative osteoarthritis), aftereffects of hemiplegia or slight tremors did not make proper use of the Wiimote Pistol impossible. This is a notable improvement over the first tests we carried out with just the Wiimote, where a majority of patients would consistently aim far too high, incapable of sufficiently bending their wrist [21]. The controller was also judged slightly too heavy by most patients, but most of them did not seem to be actually bothered. A lighter controller would definitely reduce fatigue but we saw that most patients were comfortable enough to play without feeling any pain for at least 10 minutes in a row.

\subsubsection{Arm Positioning}

Even though the pistol solved the wrist bending problem, some fatigue-inducing positions had to be corrected for a few patients: arm extended forward (subjects D and E) and aiming as with a real gun with the cannon in the line of sight (subjects $\mathrm{E}$ and $\mathrm{F}$ ). The position that 
seemed to be best adapted (arm near the body, elbow against the hip) was not spontaneously adopted by all. Having patients play in an armchair or with a tablet to support their elbow would most likely solve that problem as it would both suggest the proper position and further reduce the fatigue due to the weight of the Wiimote.

\subsubsection{Rhythm}

For some of the patients, we observed slowness in the execution of the task and a non respect of the rhythm. They knew the song they were playing and were able to sing it if asked to but were unable to play it with the proper rhythm to hear and recognize the melody. This task was probably too demanding for the patients' abilities from both a cognitive and a motor point of view. Indeed, in addition to their attention deficits (see below), most patients seemed unable to move the pointer with enough precision when asked to play faster to reproduce the actual rhythm of the song.

\subsection{Cognitive Aspects}

\subsubsection{Clear Learning Effect}

Subject $\mathrm{C}$ and subject $\mathrm{F}$ were more skilled in the use of the Wiimote and the software compared to the other participants. This resulted in a fast, if not immediate, mastery of the interface, with very short time needed to complete the various tasks and very little verbal help

provided. These two persons had the highest MMS score in the group ( $\mathrm{m}=22 / 30$ vs $14.6 / 30$ for the other participants): the severity of the cognitive impairment logically seems to play a fundamental role in the ability to learn how to use MINWii.

Subjects A, E, and G significantly improved their performance rates throughout the sessions (decrease of completion time, errors and verbal helps), which indicates a learning effect. This finding is consistent with the fact that learning new motor and perceptual skills is possible in $\mathrm{AD}$ patients because it depends on procedural memory abilities, which are better spared by 
the disease [28]. According to Buchner and Wippich [29] procedural learning skills are mastered without awareness, often simply by repeated exposure, and can be unconsciously revived from implicit memory.

\subsubsection{Effects of Cognitive Impairments}

Patient F made significantly more mistakes in the last session, which was unaccompanied. This participant quickly understood how to play, but tended to press the button continuously if he was not asked not to do it. That is probably why, in the last session, without guidance, this participant could not help pressing the trigger continuously, mostly out of the right note. $\mathrm{He}$ was the only one in the group to suffer from mixed dementia, which might explain this impulsiveness [30].

We observed a specific kind of error with some participants that consisted in pressing the trigger repeatedly with the cursor remaining at the same location on the screen even though the highlighted note had moved to another place. This kind of mistake generally followed a correct action of playing a note. We can hypothesize that the hearing of the sound is associated with "the good action to do". If patients" actions are rewarded with the musical note, they tend to replicate the same action without moving the cursor, expecting the same result, which leads to repeated errors. We can also think that a deficit in the disengagement of visual spatial attention, common in $\mathrm{AD}$ [31], can partly explain why patients do not move the cursor: maybe their attention was gripped so much that they encountered difficulties in shifting their attentional focus to the note that moved to another spot on the screen. Perhaps the colour contrast between active and inactive notes was not sufficient to allow the subjects to have a clear indication that they had to displace the cursor elsewhere on the screen to keep on playing the melody.

Otherwise, deficits in episodic and working memory, executive functions and visuo-spatial processing seem to affect the AD patients' ability to use the interface. We observed that it was 
difficult for them to accomplish two tasks simultaneously (e.g., looking at the screen while manipulating the Wiimote) or to explore the screen in order to find relevant information while remembering the purpose of the search. Some of these deficits could be compensated by repeating instructions during the exercises.

\subsubsection{Affordance of the Pistol and Disregard for the Music}

The pistol's ability to suggest its use was very efficient. Patients just needed to take the pistol in their hand to quickly understand what to do. We can borrow from the field of ergonomics the term of affordance, which refers to "the property of an object or system's action possibilities being easily discoverable" [32], to describe how intuitive the manipulation of the controller is. Here, our solution seems successful in sparing cognitively impaired patients from additional manipulation difficulties due to the "standard" Wiimote configuration.

Obviously, the pistol invites the player to aim at the screen and shoot. While its clearly visible infrared receiver on the front gives the Wiimote alone the same properties of affordance for the task by evoking a regular TV remote, the effect is far more potent with the pistol. Moreover, although it does give access to all of the buttons of the Wiimote, the pistol clearly emphasizes the trigger, which is perfect for a game like ours since we use only one button.

Contrarily to the efficiency of the controller, the music itself seemed to have little cognitive impact. Although most patients did say that the musicality of the game was motivating, they did not appear to perform much better when they were playing a song than when playing random, computer-generated melodies. For example, they did not seem to anticipate where the next note was going to be depending on its pitch, as virtually all of our healthy subjects did during informal testing. However this kind of concern deserves more investigation. First, this cognitive effect, if it exists, is bound to be subtle and hard to detect as patients are irreversibly diminished. Second, the songs were played too slowly to truly be recognizable and therefore logically had little impact. Better rhythmic assistance is offered in the other 
playing modes of MINWii, which we chose not to test in this study, and the well known melodies should better serve their facilitating purpose in this context.

\subsection{Cultural and Affective Aspects}

\subsubsection{Recoil and "Cow-boy Mode”}

During the two first sessions, subject E tended to simulate recoil whenever he pressed the trigger of the gun, which greatly impaired his accuracy. He would always say "I have to kill them" despite our explaining that there was nothing to kill because we were just playing music. Once he understood that our game had nothing to do with war, he started shooting more calmly and succeeded in playing smoothly. However he continued to call the exercise a "cow-boy game" during the remaining sessions and enjoyed making jokes about how he would get killed if he did not kill first.

Subject $\mathrm{F}$ also pressed the trigger with impulsivity during all the sessions. Although he never simulated recoil, he too would joke about the military flavour of our game and we think this fuelled his impulsivity and overall tension. He would always try to finish as fast as possible, as if the game was just a shooting challenge and had nothing to do with music, even though he clearly understood he was playing a song since he asked us to add one of his favourite tunes, Etoile des neiges, to the game's repertoire.

Clearly, the fact that our game evokes violence obscures its main objective, which is solely musical. Nevertheless, it is interesting to see that it turned out to be far less of an issue than we expected, since it had any kind of visible impact on only a few patients. Moreover, patients like subjects E and F were attracted to this "cow-boy" dimension which drew them to a game they would probably not have played otherwise. With better rhythm assistance, we should be able to divert the interest of this kind of patients to the actual music-making, thereby turning the issue of the military evocations of the Wii Pistol into an advantage.

\subsubsection{Comparison with Previous Musical Capabilities}


Patient B had more difficulties than the other participants. This patient expressed dissatisfaction during the session with the activity which she found useless and too different from playing a real instrument. She used to play the violin when she was young and tended to make comparisons with this previous musical experience and found no similarity between the game and what she already knew about music. She did not seem to understand the principle of the game, and did not manage to point at the screen and move the Wiimote to follow the notes without a lot of guidance. It resulted in a longer time needed to complete the session compared to the other participants, and to a great amount of verbal help provided. Patient B clearly expressed her wish not to continue the experiment during testing sessions 1 and 2, so we decided to stop. According to her MMS score (16/30), she was not the most cognitively impaired among the participants (range: 12-22). So severity of the disease alone cannot explain this particular result.

In addition to cognitive factors, affective factors could explain the differences between patients in terms of abilities to use the software. Affective factors are related to the user's motivation. Negative or positive self-judgment about one's own ability to use an unfamiliar technological device could have influenced the participant's performance. In the case of Patient B, who did not complete the entire test, the perceived task complexity seemed to have created dissatisfaction. Further simplifying the interfaces and the effort needed to manipulate them might be a possible way to encourage this population to use new technologies.

\subsubsection{Human Contact, Praise and Guidance}

We observed that human contact was an important factor for most of the participants. Patient C who had more ease in the use of the Wiimote was looking for intersubjective exchanges and was glad to participate in the study. She did not need much guidance but was looking for our praise. It had an effect on the time she took to complete the session, which increased for the unaccompanied session. 
Patient D had difficulties with the melody and sought a lot of help from the moderator. She was the one who needed guidance and praise the most. It helped her to increase her performance. That can explain why during the unaccompanied session we observed a significant increase of the time needed to complete the task and of the number of times verbal help was provided.

It took a certain time for patient $\mathrm{F}$ to agree to participate in the study. In the beginning he refused because he thought it was an activity for persons with dementia, so it had a pejorative connotation to him. But, after seeing his roommate, subject E, come back from the sessions and tell him about the activity with a cheerful tone, he accepted. After each session with patient $\mathrm{F}$ we observed a positive effect on his mood: he would always return to his room singing.

This MT activity had a narcissistic impact on the patients, who were feeling more selfconfident due to the guidance and comforting. It seemed to have a positive effect on the motivation to keep on coming to the sessions and on the will to increase their performance but also on their mood.

They could share a good moment and a fun activity, with professional people who were looking at them not only as demented patients but as persons testing a new technology. We observed that the quality of the human contact, praise and guidance was very powerful to catch the interest of patients with cognitive impairments.

\section{Conclusion}

The game MINWii is usable by AD patients with some guidance. There were no particular difficulties due to the controller manipulation, thus the pistol shape seems adapted for this kind of game requiring a pointing system. We could not determine a MMS score limitation, 
but the lowest MMS being 12, it allows considering a possible use with severely impaired patients. The possibility to use MINWii seems to depend on cognitive and affective factors: an important cognitive impairment can be compensated with a high motivation degree and positive responses to feed-back. However a low tolerance for failure is a factor that disrupts the possibility of learning how to use the interface and that generates dissatisfaction.

Concerning implications for future research, a long-term goal of MINWii would be to improve or at least slow down the decline of patients' cognitive abilities through regular musical practice, in a sort of musical Cognitive Stimulation Therapy (CST). However, the first goal of MINWii is different: by having AD patients participate in an activity specifically tailored to emphasize whatever skills they have left and largely compensate for their deficits, we hope to improve their self-esteem by showing them they can still take part in fun, creative and meaningful activities.

We think that MINWii, by providing a way to easily administer a simple Active Music Therapy treatment either at home or in institutions, could improve patients' quality of life and help establish music therapy as a valuable intervention, notably through the automatic collection of data for evidence-based treatment. 


\section{References}

[1] McKhann G, Drachman D, Folstein M, Katzman R, Price D, Stadlan E.M. Clinical Diagnosis of Alzheimer's Disease: Report of the NINCDS-ADRDA Work Group Under the Auspices of Department of Health and Human Services Task Force on Alzheimer's Disease. Neurology, 1984, 34(7), p.939- 944.

[2] Förstl H, Kurz A. "Clinical features of Alzheimer's disease". European Archives of Psychiatry and Clinical Neuroscience,1999, 249 (6).

[3] Graff MJ, Vernooij-Dassen MJ, Thijssen M, Dekker J, Hoefnagels WH, Rikkert MG. Community based occupational therapy for patients with dementia and their care givers: randomised controlled trial. BMJ, 2006, 9;333(7580):1196.

[4] Voigt-Radloff S, Graff M, Leonhart R, Schornstein K, Vernooij-Dassen M, Olde-Rikkert M, Huell M. WHEDA study: effectiveness of occupational therapy at home for older people with dementia and their caregivers--the design of a pragmatic randomised controlled trial evaluating a Dutch programme in seven German centres. BMC Geriatr, 2009, 2;9 p.44.

[5] Aimonetti M. Intérêt de la Wii pour les personnes âgées : oui à la Wii ! NPG Neurologie Psychiatrie - Gériatrie, 2009, 9, p.63-64.

[6] Drew, B, Waters J. Video games: Utilization of a novel strategy to improve perceptual motor skills and cognitive functioning in the non-institutionalized elderly. Cognitive Rehabilitation, 1986, 4, p.26-31.

[7] Clark JE, Lanphear AK, Riddick CC. The Effects of Videogame Playing on the Response Selection Processing of Elderly Adults. Journal of Gerontology, 1987, 42(1), p.82-85.

[8] Goldstein J, Cajko L, Oosterbroek M, Michielsen M, Van Houten O, Salverda F. Video games and the elderly. Social Behavior and Personality: an international journal, 1997, 25(4), p.345-352(8). 
[9] McGuire FA. Improving the quality of life for residents of long term care facilities through video games. Activities, Adaptation \& Aging, 1984, 6(1), p.1-7.

[10] Kautzmann LN. Introducing Computers to the Elderly. Physical \& Occupational Therapy In Geriatrics, 1990, 9(1), p.27-36.

[11] Miller G. Society for neuroscience meeting: Computer game sharpens aging minds. Science, 2005, 310, No. 5752, p. 1261.

[12] Basak C, Boot WR, Voss MW, Kramer AF. Can Training in a Real-Time Strategy Video Game Attenuate Cognitive Decline in Older Adults? Psychology and Aging. 2008 Dec; 23(4):765-777.

[13] Neufeldt C. Wii Play with elderly people. Enhancing Interaction Spaces by Social Media for the Elderly: A Workshop Report. International reports on socio-informatics , 2009, 6(3), p. $50-59$.

[14] International Organisation for Standardization (ISO), 1998. ISO 9241-11 Ergonomic Requirements for Office Work With Visual Display Terminals (VDTs)-Part 11: Guidance on Usability. ISO, Geneva, 1998.

[15] Mahendra N, Kim ES, Bayles KA, Hopper T, Cleary SJ, Azuma T. Evidence-Based Practice Recommendations for Working With Individuals With Dementia: Computer-Assisted Cognitive Interventions (CACIs). Journal of Medical Speech - Language Pathology, 2005, 13(4), p. 35- 44.

[16] Lee SH. Usability testing for developing effective interactive multimedia software: concepts, dimensions and procedures. Educ. Technol. Soc.,1999, 2: p.1436-1440 
[17] De Vitto Dabbs A, Myers BA, Mc Curry KR, Dunbar-Jacob J, Hawkins RP, Begey A, Dew MA. User-Centered Design and Interactive Health Technologies for Patients. CIN: Computers, Informatics, Nursing, 2009, 27, p.175-183.

[18] Rowland C. Cognitive Disabilities Part 2: Conceptualizing Design Considerations [online]. Web Accessibility In Mind, 2004 [cited 2010 Dec 3]. Available from: http://webaim.org/articles/cognitive/conceptualize

[19] Weakley R. An Accessibility Frontier: Cognitive disabilities and learning difficulties [online]. Web Usability, 2005 [updated 2005 Jan 30; cited 2010 Dec 3]. Available from: http://www.usability.com.au/resources/cognitive.cfm

[20] Ijsselsteijn W, Nap HH, de Kort Y, Poels K. Digital game design for elderly users. Proceedings of the 2007 conference on Future Play, Toronto, Canada, 2007, p. 17-22.

[21] Benveniste S, Jouvelot P, Péquignot R. The MINWii Project: Renarcissization of Patients Suffering from Alzheimer's Disease Through Video Game-Based Music Therapy. ICEC'10: International Conference on Entertainment Computiong. Seoul, Korea. September 7-11 2010.

[22] Guétin S, Portet F, Picot M, Pommié C, Messaoudi M, Djabelkir L, et al. Effect of Music Therapy on Anxiety and Depression in Patients with Alzheimer's Type Dementia: Randomised, Controlled Study. Dement Geriatr Cogn Disord, 2009, 28(1): p.36-46.

[23] Sacks O. Musicophilia: Tales of Music and the Brain. 1st ed. Knopf, 2007.

[24] Lewin, K. Group Decision and Social Change. Holt, Rinehart and Winston, New York, 1958.

[25] Benveniste S, Jouvelot P, Lecourt E, Michel R. Designing Wiimprovisation for mediation in Group Music Therapy with Children Suffering from Behavioral Disorders. IDC 2009: the 8th International Conference on Interaction Design and Children. Como, Italy. June 3-5 2009. 
[26] Pino M, Faucounau V, Wu YH, Boulay M, Riguet M, Sant'Anna M de, Lenoir H, Seux ML, Hugonot L, Orvoen G, Labourée F, Moulin F, Cantegreil I, Wenisch E, Rotrou J de, Rigaud AS. The LUSAGE Usability laboratory for elderly people with cognitive impairment. Gerontechnology, 2009, 8(3):185; doi:10.4017.

[27] Pino M, Boulay M, Faucounau V, Wu YH, Rigaud AS. Usability assessment methodology for elderly people with cognitive impairment: the LUSAGE laboratory experience. Gerontechnology, 2010, 9(2):347 ; doi :10.4017/gt.2010.09.02.313.00.

[28] Van Halteren-van Tilborg, I.A.D.A., Scherder, E.J.A., Hulstijn W. Motor-Skill Learning in Alzheimer's Disease: A Review With an Eye to the Clinical Practice. Neuropsychol. Revue, 2007, 17(3), p. 203-212.

[29] Buchner A, Wippich W. Differences and commonalities between implicit learning and implicit memory. In: Stadler MA \& Frensch PA Eds. Handbook of implicit learning. Thousand Oaks, CA.: Sage Publications, 1998.

[30] Moorhouse P, Song X, Rockwood K, Black S, Kertesz A, Gauthier S an Feldman H. Executive dysfunction in vascular cognitive impairment in the consortium to investigate vascular impairment of cognition study. Journal of the Neurological Sciences, 2010, 288, Issues 1-2, p.142-146.

[31] Rösler A, Mapstone ME, Hays AK, Mesulam MM, Rademaker A, Gitelman DR, Weintraub S. Alterations of visual search strategy in Alzheimer's disease and aging. Neuropsychology, 2000, Jul;14(3), p.398-408.

[32] Norman DA. Affordances, Conventions and Design. Interactions, 1999, 6(3) p.38-43, May 1999, ACM Press. 


\begin{tabular}{|c|c|c|c|c|c|}
\hline Participants & Gender & Age & $\begin{array}{c}\text { Sociocultural } \\
\text { status }\end{array}$ & MMSE & Musical \\
& & experience & no \\
\hline A & M & 94 & $5 / 7$ & $13 / 30$ & yes \\
\hline B & F & 90 & $5 / 7$ & $16 / 30$ & yes \\
\hline C & F & 89 & $6 / 7$ & $22 / 30$ & yes \\
\hline D & F & 89 & $7 / 7$ & $15 / 30$ & yes \\
\hline E & M & 93 & $7 / 7$ & $17 / 30$ & no \\
\hline F & M & 77 & $4 / 7$ & $15 / 30$ & yes \\
\hline G & F & 88 & $5 / 7$ & $12 / 30$ & \\
\hline
\end{tabular}

Table 1: socio-demographics data, MMSE, musical experience 


\begin{tabular}{|c|c|c|c|c|}
\hline \multirow{2}{*}{ Subject } & \multicolumn{5}{|c|}{ Session } \\
\cline { 2 - 5 } & $\mathbf{1}$ & $\mathbf{2}$ & $\mathbf{3}$ & $\mathbf{4}$ \\
\hline $\mathbf{A}$ & 2 & 1 & 0 & $*$ \\
\hline B & 8 & 7 & $*$ & $*$ \\
\hline $\mathbf{C}$ & 0 & 0 & 0 & 0 \\
\hline $\mathbf{D}$ & 1 & 0 & 0 & 0 \\
\hline $\mathbf{E}$ & 0 & 0 & 0 & 0 \\
\hline $\mathbf{F}$ & 0 & 0 & 0 & 0 \\
\hline $\mathbf{G}$ & 1 & 0 & 0 & 1 \\
\hline
\end{tabular}

Table 2: Number of times that physical help was provided by the moderator ${ }^{2}$

\footnotetext{
${ }^{2}$ Missing data is signaled with a *
} 


\begin{tabular}{|c|c|c|}
\hline \multirow{2}{*}{ Subject } & \multicolumn{2}{|c|}{ Satisfaction score (/28) } \\
\cline { 2 - 3 } & $\mathbf{1}$ & $\mathbf{2}$ \\
\hline A & 20 & 18 \\
\hline B & 16 & 19 \\
\hline C & 21 & 16 \\
\hline D & 15 & 24 \\
\hline E & 17 & 20 \\
\hline F & 18 & 18 \\
\hline G & 16 & \\
\hline
\end{tabular}

Table 3: Satisfaction score after the training session (1) and after the third testing session (2) ${ }^{3}$

\footnotetext{
${ }^{3}$ Missing data is signaled with a *
} 


\section{Figures}

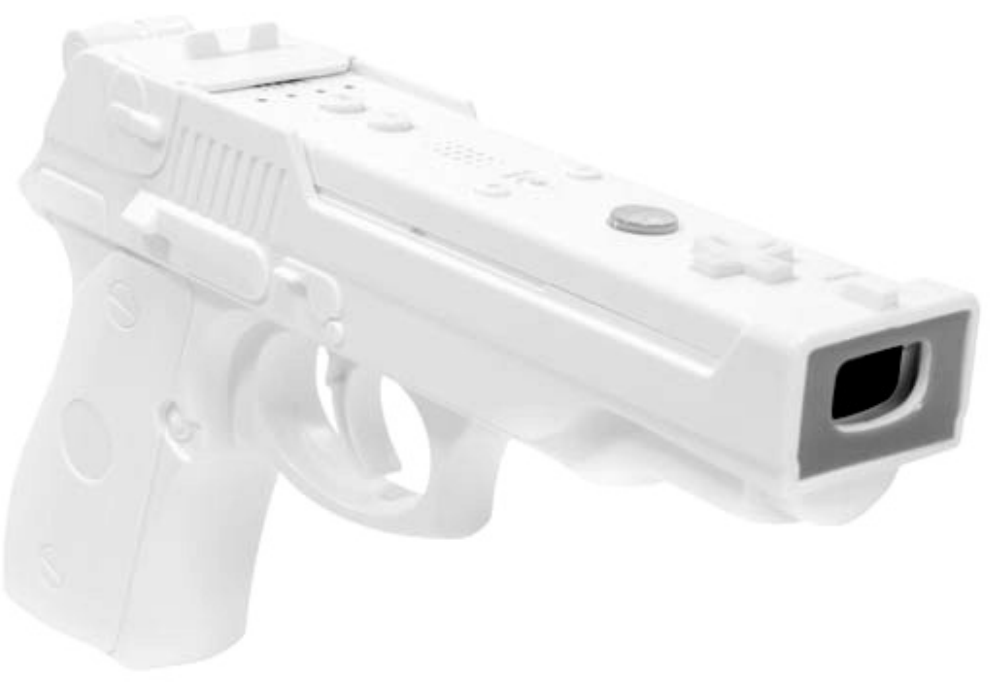

Figure 1: The Wiimote Pistol.

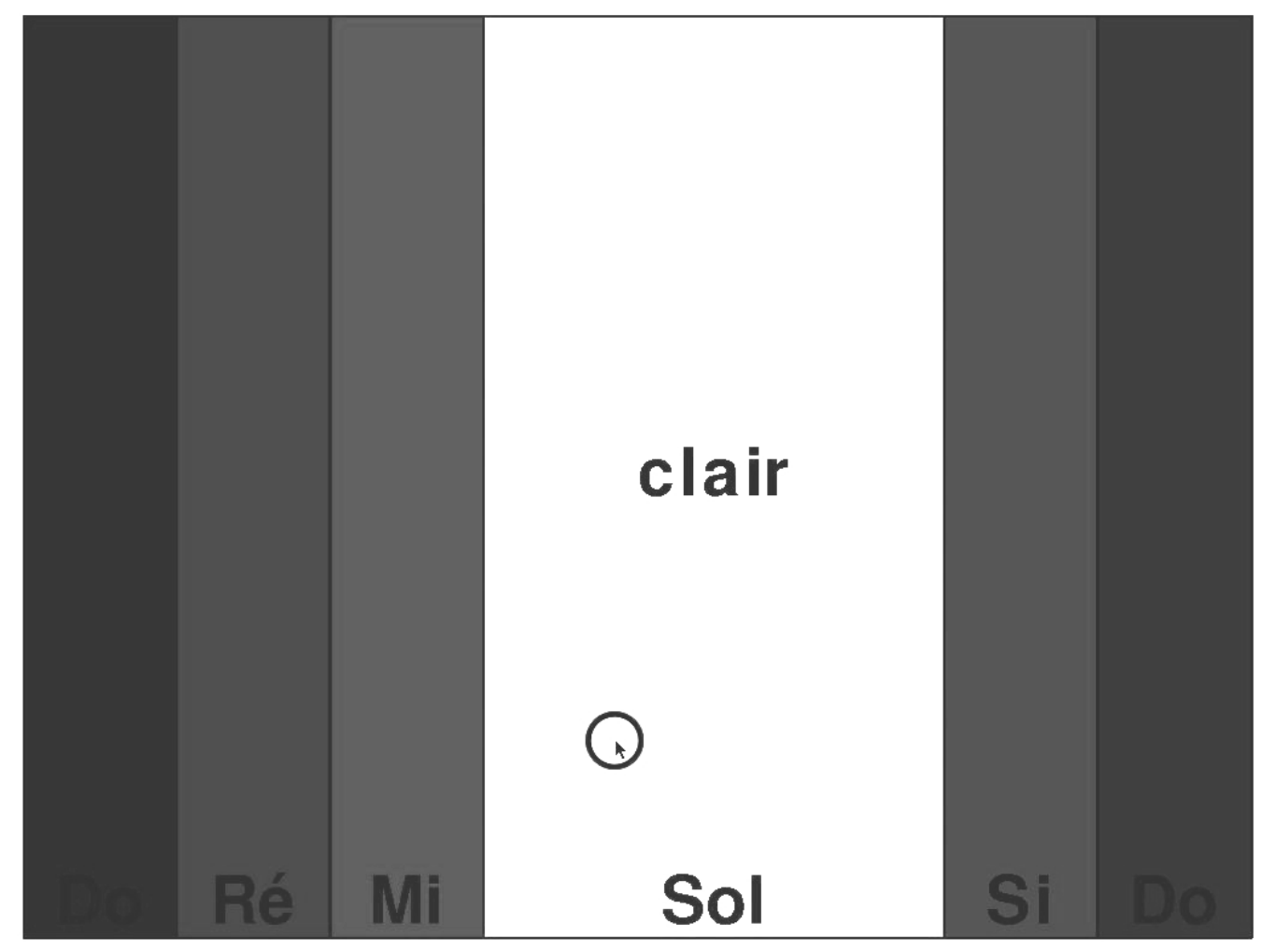

Figure 2: A screen capture from one of the sessions. 


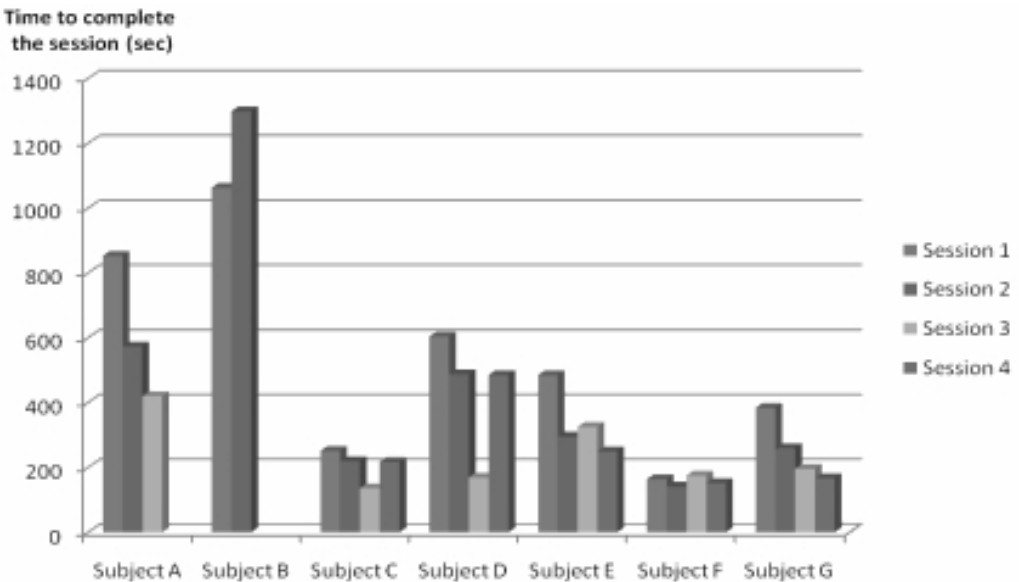

Figure 3: Time to complete each session in seconds.

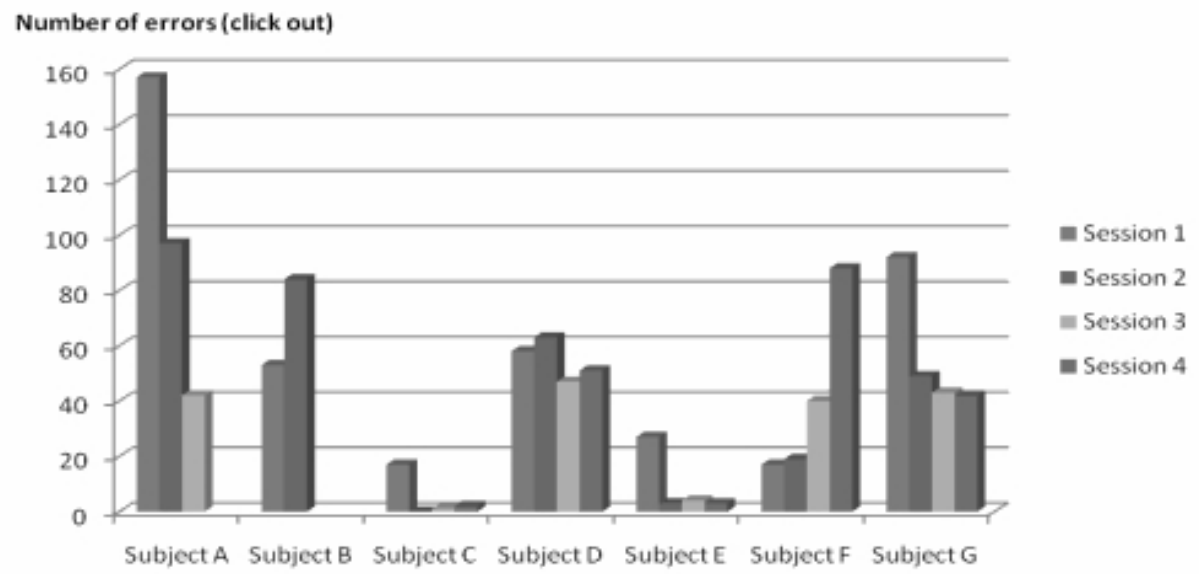

Figure 4: Number of errors made by each participant in the testing sessions.

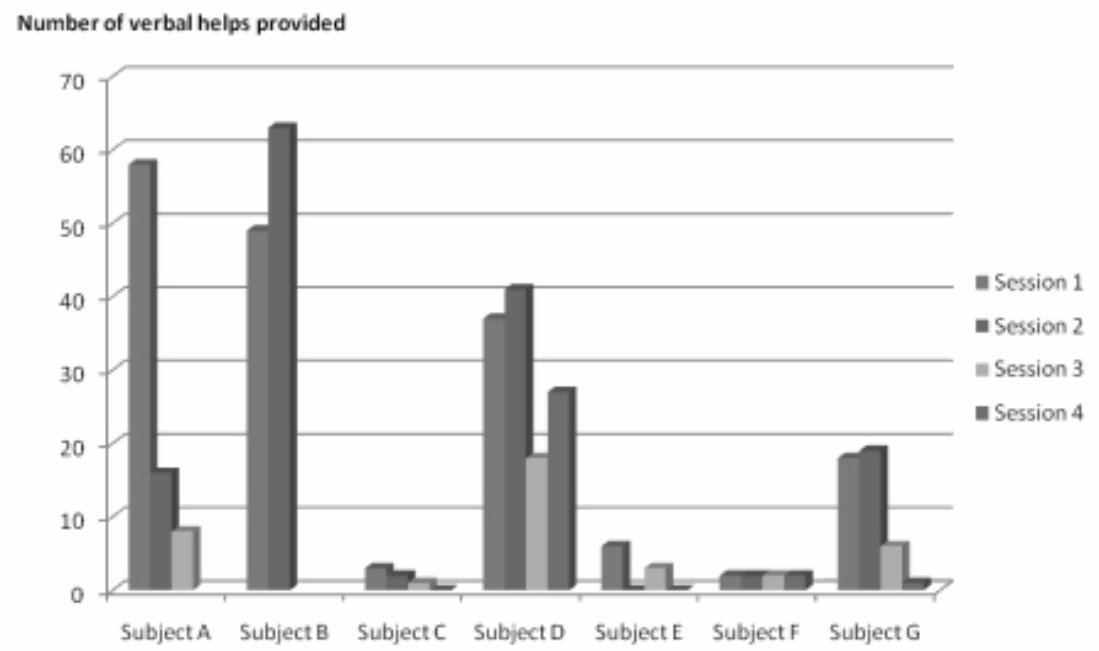

Figure 5: Number of times that help was provided to the patients during the testing sessions. 